\title{
In vitro and in vivo chemosensitizing effect of cyclosporin A on an intrinsic multidrug-resistant rat colon tumour
}

\author{
W. Van de Vrie ${ }^{1,2}$, E.E.O. Gheuens ${ }^{3}$, N.M.C. Durante ${ }^{1,2}$, E.A. De Bruijn ${ }^{3}$, R.L. Marquet $^{2}$, A.T. Van Oosterom ${ }^{3}$, \\ A.M.M. Eggermont ${ }^{1}$ \\ 1 Department of Surgical Oncology, Rotterdam Cancer Institute, Groene Hilledijk 301, 3075 EA Rotterdam, The Netherlands \\ ${ }^{2}$ Laboratory for Experimental Surgery, Erasmus University, PO Box 1738, 3000 DR Rotterdam, The Netherlands \\ ${ }^{3}$ Laboratory of Cancer Research and Clinical Oncology, Antwerp University, B-2610 Wilrijk, Belgium
}

Received: 23 September 1992/Accepted: 18 December 1992

\begin{abstract}
Colon tumours are intrinsically resistant to chemotherapy and most of them express the multidrug transporter P glycoprotein (Pgp). Whether this Pgp expression determines their resistance to anticancer agents in patients is not known. We report here on the reversibility of intrinsic multidrug resistance in a syngeneic, solid tumour model. CC531 is a rat colon carcinoma that expresses Pgp, as was shown with the monoclonal antibody C-219. In vitro the sensitivity to doxorubicin, daunorubicin and colchicine was enhanced by the addition of the chemosensitizers verapamil and cyclosporin A (CsA), while the sensitivity to cisplatin was not enhanced. In a daunorubicin accumulation assay verapamil and CsA enhanced the daunorubicin content of CC531 cells. In vivo CsA was injected intramuscularly for 3 consecutive days at a dose of $20 \mathrm{mg} \mathrm{kg}^{-1}$ day $^{-1}$. This resulted in whole-blood CsA levels above $2 \mu \mathrm{mol} / \mathrm{l}$, while intratumoral CsA levels amounted to $3.6 \mu \mathrm{mol} / \mathrm{kg}$. In a subrenal capsule assay the maximal tolerable dose of doxorubicin $(4 \mathrm{mg} / \mathrm{kg})$ significantly reduced tumour growth. Doxorubicin at $3 \mathrm{mg} / \mathrm{kg}$ was not effective, but in combination with CsA this dose was as effective as $4 \mathrm{mg} / \mathrm{kg}$ doxorubicin. These experiments show that adequate doses of the chemosensitizing drug CsA can be obtained in vivo, resulting in increased antitumoral activity of doxorubicin in vivo. The in vitro and in vivo data together suggest that the chemosensitization by CsA is mediated by Pgp. This finding may have implications for the application of CsA and CsA-like chemosensitizers in the clinical setting.
\end{abstract}

Key words: Cyclosporin A - Multidrug resistance $-\mathrm{P}$ glycoprotein - Chemosensitizing - In vivo

Work was supported by the Dr Daniël den Hoed Foundation, Rotterdam, the Netherlands and Behring AG, Amsterdam, The Netherlands, and Belgian bank ASLK

Abbreviations: Cisplatin, cis-diaminedichloroplatinum; CsA, cyclosporin A; MDR, multidrug resistance; MTT, 3-(4,5-dimethylthiazol-2-yl)2,5-diphenyltetrazolium bromide; PBS, phosphate-buffered saline; Pgp, P glycoprotein; SRCA, subrenal capsule assay

Correspondence to: A.M.M. Eggermont, Department of Surgical Oncology, Rotterdam Cancer Institute, Groene Hilledijk 301, 3075 EA Rotterdam, The Netherlands

\section{Introduction}

The phenomenon of multidrug resistance (MDR) to anticancer agents can be an intrinsic characteristic of tumours, or can be acquired by tumours during the course of chemotherapy. Among the tumours that intrinsically have a very low response rate to chemotherapy are colon cancer, renal cell cancer, hepatocellular cancer and adrenocortical cancer. These tumours have high expression levels of the gene for multidrug resistance, $m d r 1$, at a high frequency (Goldstein et al. 1989). The tissues from which they arise also have a high level of $m d r l$ expression (Fojo et al. 1987). In these tissues the gene product of $m d r 1$, P glycoprotein (Pgp), may function as an efflux pump for xenobiotics. It is striking that organs with the highest expression of $m d r l$ all have excretory functions and that within these organs Pgp is principally found in cells lining excretory lumina (Thiebaut et al. 1987). Whether $m d r$ expression in intrinsic MDR tumours is the most important factor determining their resistance to chemotherapy, and whether blocking of Pgp or suppression of $m d r$ expression can result in enhancement of cytotoxicity of anticancer drugs in the clinical situation, are still under study.

Several drugs have been reported to reverse MDR in vitro. One of the most effective resistance-modifying agents is the immunosuppressive drug cyclosporin A (CsA) (Ford and Hait 1990). Many in vitro studies have shown an increase in cytotoxity to MDR cell lines when CsA is added to drugs that are affected by the MDR cross-resistance pattern, like doxorubicin, vincristine and colchicine (Boesch et al. $1991 \mathrm{~b}$; Gavériaux et al. 1989; Twentyman et al. 1990). CsA, like other resistance-modifying agents, acts as a chemosensitizer almost only against MDR cell lines; the cytotoxicity to parental cell lines that do not express Pgp is not influenced. On some cell lines CsA alone has antiproliferative and/or cytotoxic effects, especially at higher doses of CsA (Twentyman et al. 1992).

Compared to the abundance of in vitro data on the role of Pgp and the reversal of MDR by chemosensitizers, very few data on their value in vivo have been published, especially concerning their role in solid tumours. Most in vivo studies have been carried out with ascites tumours. In these models 
intraperitoneally floating tumour cells are treated with intraperitoneal injections of drugs. In solid tumours a prerequisite is achieving effective drug concentrations at the tumour site by a vascular route.

We investigated the question of intrinsic MDR in a syngeneic, solid tumour model. We report here on the chemosensitizing effects of CsA in vitro and in vivo on an intrinsic MDR rat colon carcinoma.

\section{Materials and methods}

Animals. Male rats of the inbred WAG/RIJ (RT1 $\mu$ ) strain were obtained from Harlan-CPB (Austerlitz, The Netherlands). Animals were bred under specific-pathogen-free conditions and fed standard rat chow (Hope Farms, Woerden, The Netherlands) and water ad libitum. In the experiments rats 12-18 weeks old, weighing $220-280 \mathrm{~g}$, were used.

Tumours. CC531 is a colon carcinoma, which was induced chemically in the WAG rat with 1,2-dimethylhydrazine. The tumour, a moderately differentiated adenocarcinoma, is weakly immunogenic and transplantable in syngeneic rats (Marquet et al. 1984). In vitro the cell line grows as a monolayer in Dulbecco's modified Eagle's medium supplemented with $5 \%$ fetal calf serum, aspartic acid $(0.1 \mathrm{mM})$, and glutamic acid $(0.3 \mathrm{~m} M)$, all obtained from Gibco (Paisley, UK), in a humidified atmosphere of $5 \% \mathrm{CO}_{2} / 95 \%$ air at $37^{\circ} \mathrm{C}$. Regular screening for Mycoplasma infection was performed. Cells were isolated by trypsinization; viability, determined by trypan blue exclusion, was over $90 \%$ in all experiments.

The human ovarian carcinoma cell lines A2780 and $2780^{\mathrm{AD}}$ (Rogan et al. 1984) were grown in complete medium. $2780^{\mathrm{AD}}$, a multidrug-resistant cell line with a high level of Pgp expression, was grown in the presence of $1 \mu M$ doxorubicin. This cell line was used as a positive control in immunofluorescence studies, while the parental line, A2780, was used as a negative control.

Chemicals. Cyclosporin A was obtained from Sandoz, Basel, Switserland; doxorubicin (Adriablastina) from Farmitalia, Nivelles, Belgium; daunorubicin, colchicine, cis-diaminedichloroplatinum (cisplatin), verapamil and MTT [3-(4,5-dimethylthiazol-2-yl)-2,5-diphenyltetrazolium-bromide] from Sigma Chemical, St. Louis, MO; and dimethylsulphoxide from Merck, Darmstadt, Germany.

In vitro cytotoxicity assay. We determined chemosensitivity in vitro by the MTT assay, essentially carried out as described by Carmichael et al. (1987). In brief, in 48-well culture plates (Costar, Cambridge, Mass.) 1500 cells were plated in $500 \mu \mathrm{l}$ complete medium. Drugs were dissolved in $0.9 \% \mathrm{NaCl}$. To each well $250 \mu \mathrm{l}$ drug solution was added, using a fixed concentration of the chemosensitizer and graded concentrations of the drugs. Cells were grown at $37^{\circ} \mathrm{C}$ in $5 \% \mathrm{CO}_{2}$ humidified air. After 4 days $150 \mu \mathrm{l}$ MTT, dissolved in PBS (phosphate-buffered saline) at a concentration of $2 \mathrm{mg} / \mathrm{ml}$ was added to each well. After an incubation period of $4 \mathrm{~h}$ the supernatant was carefully removed and $250 \mu \mathrm{l}$ dimethylsulphoxide was pipetted to each well. Plates were placed in a microplate shaker for $5 \mathrm{~min}$. The content was pipetted into 96 -well plates in order to read the absorbance at $570 \mathrm{~nm}$ in an automatic microtiter reader (EAR-400). Survival was calculated using the formula: survival $=$ (test well $/$ control $) \times 100 \%$. The drug concentration reducing the absorbance to $50 \%$ of control $\left(\mathrm{IC}_{50}\right)$ was determined from the graphs. Sensitization ratios were determined by dividing the $\mathrm{IC}_{50}$ in the absence of the resistance-modifying agent by the $\mathrm{IC}_{50}$ in the presence of the chemosensitizer.

Drug accumulation. In order to determine the accumulation of daunorubicin, cells were incubated with $1 \mu \mathrm{g} / \mathrm{ml}$ daunorubicin for $1 \mathrm{~h}$ at $37^{\circ} \mathrm{C}$. The content of the fluorescent drug in individual cells was measured on the FACStar Plus flow cytometer (Becton Dickinson, Mountain View, Calif.), equipped with a $4-\mathrm{W}$ argon-ion laser tuned to $488 \mathrm{~nm}$ with $300 \mathrm{~mW}$ power. Orange fluorescence pulses were collected through a 575/26-nm bandpass filter. Results were calculated using the FACStar Plus research software (Gheuens et al. 1991). Enhancement of daunorubicin accumulation was tested by adding CsA $(5 \mu M)$ and/or verapamil
$(6.6 \mu M)$ to the incubation medium. Results are presented as mean fluorescence intensity.

Immunofluorescence. Pgp expression was determined with the specific anti-Pgp monoclonal antibody C-219, which recognizes an internal epitope of Pgp (Kartner et al. 1985). Single-cell suspensions of A2780, $2780^{\mathrm{AD}}$, and CC531 were fixed with methanol $70 \%$ for $10 \mathrm{~min}$ at $-20^{\circ} \mathrm{C}$. Cells were washed three times in PBS and resuspended in PBS with $1 \%$ bovine serum albumin (Centocor, Leiden, The Netherlands). Next, cells were incubated with the monoclonal antibody C-219-FITC (fluorescein isothiocyanate conjugate; P-glyco-CHEK, Centocor) diluted 1:100, for $60 \mathrm{~min}$ on ice. IgG2a-FITC was used as a control antibody, to determine the aspecific and/or autofluorescence of the cells. After three washings in PBS, cells were analysed on the FACStar Plus flow cytometer using green fluorescence pulses, collected through a $530 / 30$ nm bandpass filter.

In vivo assay. Solid tumours of the CC531 cell line were obtained by intraperitoneal inoculation of $5 \times 10^{6}$ tumour cells. After 30-40 days a rat carrying a large tumour mass was sacrificed and a viable tumour part was excised and divided into small pieces. In a subrenal capsule assay (SRCA) tumour pieces weighing 6-8 mg were implanted under the capsule of the kidneys. Rats were matched for implanted tumour weight in the different treatment groups. On the same day CsA treatment was started. CsA, dissolved in olive oil, was injected intramuscularly into the hind leg daily, for 3 consecutive days at a dose of $20 \mathrm{mg} / \mathrm{kg}$, in order to generate sustained high levels of CsA. On day 3 , rats were injected with $3 \mathrm{mg} / \mathrm{kg}$ or $4 \mathrm{mg} / \mathrm{kg}$ doxorubicin, or PBS in control rats. After 10 days animals were sacrificed and tumours were enucleated and weighed. All experimental groups consisted of six rats and all animals were evaluable.

Cyclosporin A levels. CsA levels in vivo were determined with the Emit cyclosporin assay (Syva, Palo Alto, Calif.) on the ELAN analyser (Eppendorf, Hamburg, Germany). This homogeneous enzyme immunoassay is designed for measuring CsA levels in whole blood. Blood samples were taken $24 \mathrm{~h}$ after the third injection of CsA. Whole blood samples $(100 \mu \mathrm{l})$ were mixed with $200 \mu 1100 \%$ methanol, which solubilizes CsA. The samples were centrifuged and aliquots of the supernatant containing the CsA were diluted with Emit cyclosporin diluent before assaying. In order to measure intratumoral CsA levels, tumours were grown under the renal capsule for 10 days. On day 7, 8 and 9 CsA $(20 \mathrm{mg} / \mathrm{kg})$ was administered intramuscularly. On day 10 rats were sacrificed and tumours were enucleated without renal tissue. Tumours were crushed in a small tube in $300 \mu \mathrm{l}$ methanol with a pestle for $3 \mathrm{~min}$. Then $200 \mu \mathrm{l}$ solution was mixed with $100 \mu \mathrm{l}$ normal rat whole blood and assayed as a blood sample. The results were corrected for dilution steps and calculated per kilogram tumour tissue, while the plasma and whole blood levels are presented per liter. As the weight of 11 whole blood is $1.06 \mathrm{~kg}$, the results of the tissue levels and the blood levels are comparable. Because the CsA levels appeared to be very high, an additional dilution step was necessary to reach the measurable range of the assay. Blood samples and tumour samples were taken from three rats and represented individually in the graph.

Statistics. Statistical significance was determined with SPSS/PC+, using the Mann-Whitney $U /$ Wilcoxon rank-sum $W$ test. $P<0.05$ was considered significant. Results are presented as means with standard deviations.

Ethical approval. The experimental protocols adhered to the rules laid down in The Dutch Animal Experimentation Act (1977) and the Guidelines on the Protection of Experimental Animals published by the Council of the E.C. (1986). Specific protocols were approved by the Committee on Animal Research of the Erasmus University, Rotterdam.

\section{Results}

\section{In vitro chemosensitizing effect}

In the first tests we used the best-known chemosensitizer, verapamil. At a concentration of $6.6 \mu M$ growth inhibition of 
Table 1. Chemosensitizing effect of verapamil (VPL) on growth inhibition by drugs in CC531 cells

\begin{tabular}{llll}
\hline Drug & $\mathrm{IC}_{50}-\mathrm{VPL}^{\mathrm{a}}$ & $\mathrm{IC}_{50}+\mathrm{VPL}^{\mathrm{a}}$ & Sensitization ratio $^{\mathrm{b}}$ \\
\hline Colchicine & $0.081( \pm 0.021)$ & $0.028( \pm 0.001)$ & 2.9 \\
Daunorubicin & $0.200( \pm 0.113)$ & $0.030( \pm 0.002)$ & 6.7 \\
Cisplatin & $0.600( \pm 0.120)$ & $0.865( \pm 0.087)$ & 0.7
\end{tabular}

${ }^{a}$ The drug concentration that results in a $50 \%$ reduction of the absorbance in the MTT assay; the values in parentheses are standard deviations ${ }^{b}$ The mean sensitization ratio is shown. All experiments were carried out at least three times

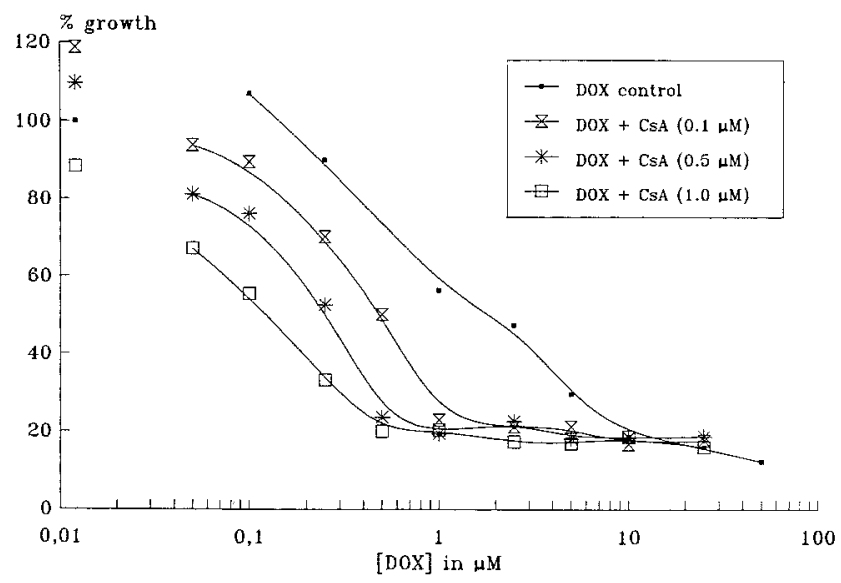

Fig. 1. Dose/response curves of the cell line CC531 to doxorubicin $(D O X)$ in the absence or presence of various concentrations of cyclosporin A (CsA) determined in the MTT assay. Cell number, measured as absorbance in the colorimetric assay, is represented as a percentage of the control cell growth on the $y$ axis
Table 2. Effect of chemosensitizers on daunorubicin (DNR) accumulation

\begin{tabular}{ll}
\hline Drugs & DNR content \\
\hline DNR & 100 \\
DNR+CsA & $211 \pm 38$ \\
DNR+VPL & $193 \pm 20$ \\
\hline
\end{tabular}

a Numbers represent the mean fluorescence intensity of daunorubicin in CC531 cells after incubation with and without chemosensitizers. Daunorubicin: $1 \mu \mathrm{g} / \mathrm{ml}$; cyclosporin A (CsA) $5 \mu M$; verapamil (VPL) $6.6 \mu M$. The fluorescence of daunorubicin alone is arbitrarily defined as 100. The experiments were repeated at least twice

the cell line CC531 by drugs like daunorubicin and colchicine was enhanced. Verapamil was not able to amplify the growth-inhibiting effect of cisplatin. In contrast, some growth enhancement was observed (Table 1). At lower concentrations the efficacy of verapamil diminished rapidly: at a concentration of $1 \mu M$ only a small chemosensitizing effect was seen. Next we tested the chemosensitizing potential of CsA; in Fig. 1 a representative experiment is shown. CsA had a concentration-dependent chemosensitizing effect on growth inhibition by doxorubicin and was active at concentrations as low as $0.1 \mu M$. The mean sensitization ratio of 0.5 $\mu M$ CsA to doxorubicin cytotoxicity was 6.6.

\section{Enhancement of drug accumulation}

Table 2 shows the results of the daunorubicin accumulation study. The mean fluorescence intensity, a measure for the intracellular daunorubicin quantity, calculated from the histo-

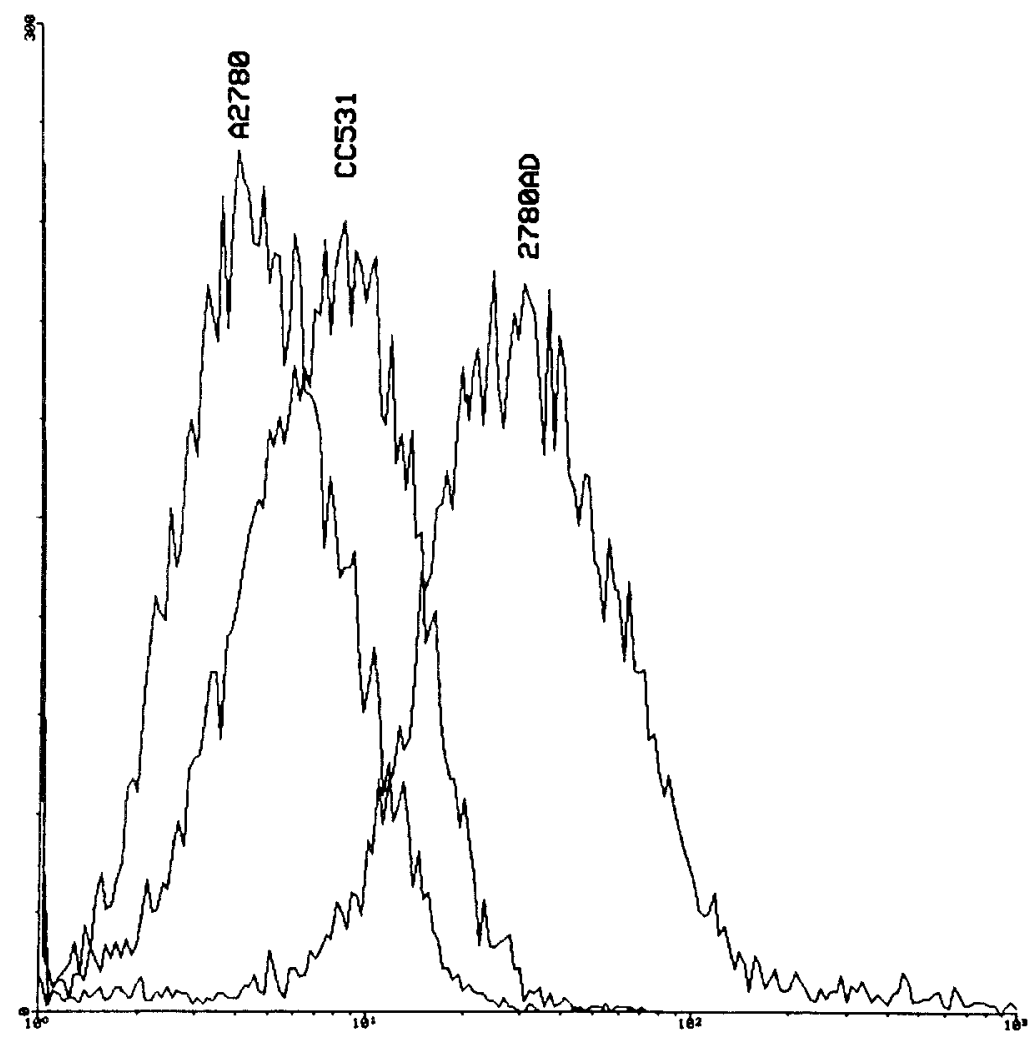

Fig. 2. $P$ glycoprotein expression in $A 2780,2780^{\mathrm{AD}}$ and CC531 cells determined by flow cytometry with the monoclonal antibody C-219. The figure shows cell count on the $x$ axis (linear scale) and fluorescence intensity (fluoresceinisothiocyanate-labelled C-219) on the $y$ axis (logarithmic scale) 


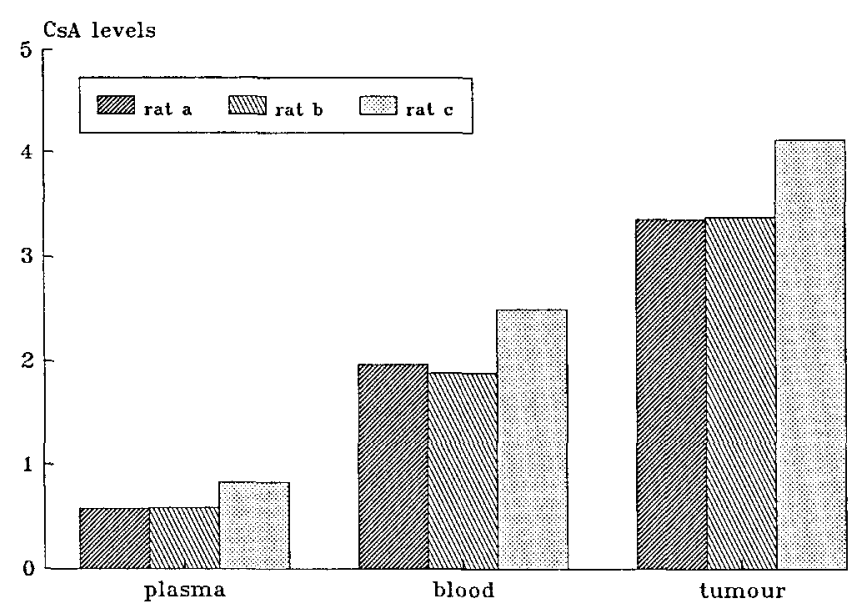

Fig. 3. Cyclosporin A (CsA) levels in plasma, whole blood and in CC531 tumours determined with the Emit cyclosporin assay. The results of three animals are represented individually. The units used for CsA levels in plasma and whole blood are $\mu \mathrm{mol} / \mathrm{l}$, in tumour tissue $\mu \mathrm{mol} / \mathrm{kg}$

grams, increased under the influence of $5 \mu M$ CsA 2.1 times. At this concentration CsA was as effective as $6.6 \mu M$ verapamil.

\section{P glycoprotein expression}

Ideally immunofluoresence studies should be carried out with a monoclonal antibody that recognizes an external epitope of a membrane protein. Using an antibody that recognizes an internal epitope requires membrane disturbance by fixation with the drawback of possible loss of intensity because of epitope loss by this fixation. However, for rat Pgp there is no monoclonal antibody available that recognizes an external epitope, as MRK-16 is humanspecific and the antibodies HYB-241 and 265/F4 do not recognize rat Pgp (unpublished observations). Therefore we tested with C-219, an antibody widely used to determine Pgp expression. In Fig. 2 a distinct difference is seen between the non-Pgp-expressing $\mathrm{A} 2780$, and the Pgp-expressing $2780^{\mathrm{AD}}$. The fluorescence peak of CC531 cells bound to C-219-FITC lies between that of the two control cell lines, just to the right of A2780, demonstrating the Pgp expression in CC531 cell.

\section{In vivo cyclosporin A levels}

Because we had no data on the bio-availibility of CsA in tumours, we chose to administer CsA at a higher dose than necessary to reach a chemosensitizing effect on CC531 cells in vitro. With the injection of $20 \mathrm{mg} \mathrm{kg}^{-1}$ day $^{-1}$ on 3 consecutive days, an intramuscular depot was generated, which gave sustained high levels of CsA. Whole blood levels, determined $24 \mathrm{~h}$ after the last injection of CsA (about $2 \mathrm{~h}$ before the administration of doxorubicin), amounted to $2.1( \pm 0.2) \mu \mathrm{mol} / 1$. In a separate exeriment blood and intratumoral CsA levels were compared. The CsA level in whole blood was again $2.1 \mu \mathrm{mol} / \mathrm{l}$. Intratumoral CsA levels, measured with the same method, amounted to $3.6 \mu \mathrm{mol} / \mathrm{kg}$, which is higher than in whole blood. See Fig. 3.

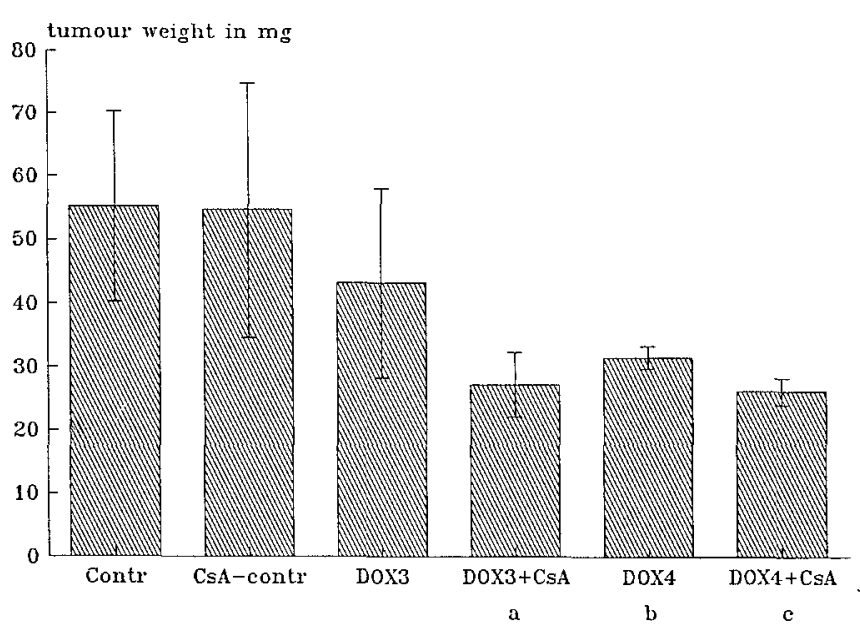

Fig. 4. Effect of doxorubicin (DOX) and/or the chemosensitizer cyclosporin $\mathrm{A}\left(C_{S} A\right)$ on weights of CC531 tumours in the subrenal capsule assay experiment. Contr, control, no drug treatment; CsA-contr, only treatment with $\mathrm{CsA} ; D O X 3$, rats treated with $3 \mathrm{mg} / \mathrm{kg}$ doxorubicin; $D O X 3+C s A$, rats treated with $3 \mathrm{mg} / \mathrm{kg}$ doxorubicin, and CsA; DOX4, rats treated with $4 \mathrm{mg} / \mathrm{kg}$ doxorubicin, DOX $4+\mathrm{CsA}$, rats treated with 4 $\mathrm{mg} / \mathrm{kg}$ doxorubicin, and CsA. The following groups were significantly smaller compared to other groups (determined with the Mann-Whitney $U /$ Wilcoxon rank-sum $W$ test): (a) DOX $3+$ CsA versus Contr $(P=0.0039)$, CsA-contr $(P=0.0039)$, and DOX3 $(P=0.0163) ;(b)$ DOX4 versus Contr $(P=0.0039)$, and CsA-contr $(P=0.0039)$; $(c)$ DOX4+CsA versus Contr $(P=0.0039)$, CsA-contr $(P=0.0039)$, DOX3 $(P=0.02)$, and DOX4 $(P=0.0039)$

\section{In vivo chemosensitizing effect}

In the SRCA doxorubicin alone, administered at the maximal tolerable dose of $4 \mathrm{mg} / \mathrm{kg}$, significantly inhibited tumour growth (Fig. 4). A lower dose of $3 \mathrm{mg} / \mathrm{kg}$ had no significant growth-retarding effect. In combination with $\mathrm{CsA}$ both doses of doxorubicin were significantly more effective compared to treatment with the respective doses of doxorubicin alone. Treatment with CsA alone had no effect on tumour growth. A repeat experiment with $4 \mathrm{mg} / \mathrm{kg}$ doxorubicin showed a significant chemosensitizing effect of CsA also at the $4 \mathrm{mg} / \mathrm{kg}$ dose level.

\section{Discussion}

In this study we show the feasibility of overcoming intrinsic MDR in a rat colon adenocarcinoma in vivo. We believe that the CC531 tumour provides a good, syngeneic, solid tumour model for studying intrinsic MDR. In vivo CC531 is very resistant to most anticancer drugs and only a moderate sensitivity to cisplatin has been described (Los et al. 1990). In our experiments a significant growth-retarding effect could be obtained by using doxorubicin, but only when used at the maximal tolerable dose of $4 \mathrm{mg} / \mathrm{kg}$, while no significant growth inhibition was observed at lower dosage. In in vitro cytotoxicity tests the addition of chemosensitizers enhanced the growth-inhibiting effect of daunorubicin, doxorubicin and colchicine, drugs of the cross-resistance pattern of MDR, whereas the cytotoxicity of cisplatin was not enhanced by CsA. We demonstrated by flow cytometry that co-incubation of daunorubicin with chemosensitizers like CsA and verapamil results in an enhanced accumulation of daunorubicin in 
cells. A distinct expression of Pgp was shown by immunofluorescence. These data indicate that CC531 has the typical MDR phenotype.

Of the drugs that are able to reverse MDR in vitro, verapamil is the best known and most intensely studied. However, levels of verapamil necessary to reverse MDR in vitro, about $5 \mu M$, can not be reached in patients because of prohibitive cardiovascular toxicity (Pennock et al. 1991). We chose CsA as a chemosensitizer because several investigators reported a higher effectivity on an equimolar basis of CsA over verapamil (Boesch et al. 1991b; Silberman et al. 1989; Twentyman et al. 1990), a result we also found with the CC531 cell line. The second reason we chose CsA was that the concentration of CsA necessary in vitro to overcome drug resistance is achievable without intolerable side-effects in vivo in humans (Verweij et al. 1991; Sonneveld et al. 1992). However, one can not translate in vitro concentrations directly into doses required in vivo, as pharmacological aspects may play an important role in the bio-availability of the drug (Kaye 1990), e.g. in vivo over $95 \%$ of CsA is bound to proteins or cells. Therefore we decided to administer CsA at a higher dose than required to achieve a chemosensitizing effect in our in vitro experiments. After 3 days of intramuscular administration, CsA levels in whole blood obtained in the in vivo experiments were above $2 \mu \mathrm{mol} / \mathrm{l}$. Interestingly, measured with the same cyclosporin assay, intratumoral levels of CsA amounted to 3.6 $\mu \mathrm{mol} / \mathrm{kg}$, which suggests that in solid tumours CsA levels may be even higher than in whole blood. This means that adequate levels of the chemosensitizer CsA can be reached at the tumour site by a vascular route. In vivo this dose had neither a growth-retarding, nor a growth-stimulating effect on the tumour: in the SRCA, tumours in the control group or tumours treated with CSA alone had similar weights.

In this intrinsic MDR model we show that CsA can have an effective chemosensitizing effect on doxorubicin in vivo. In the SRCA experiment rats treated with the combination of CsA and doxorubicin had significantly smaller tumours compared to all other groups and also compared to the rats treated with doxorubicin alone. Adding CsA to doxorubicin rendered a suboptimal dose of $3 \mathrm{mg} / \mathrm{kg}$ doxorubicin effective, and the activity of an effective dose of $4 \mathrm{mg} / \mathrm{kg}$ was enhanced by combination with CsA. The differences in standard errors between the experimental groups, with larger errors in the control groups and less variation in results in the treated groups, is a phenomenon that is often seen in experimental pharmacology. Probably this is due to the logarithmic growth of tumours, which is attenuated for some time in effectively treated groups, resulting in smaller tumours with inherently smaller standard errors.

Together with the in vitro data, demonstrating Pgp expression, enhancement of drug uptake and increased growth inhibition in CC531 cells by the addition of CsA, these findings furnish evidence for direct MDR reversal at the cellular tumour level. However, an alternative explanation, CsA altering drug pharmacokinetics (Sikic et al. 1992), can not be ruled out. As Pgp expression is found in the kidneys, especially in the renal tubules (Thiebaut et al. 1987), blocking of this efflux pump may diminish excretion of anticancer drugs and, via higher and more prolonged blood levels, cause indirect enhanced exposure of cells to drugs (Sikic et al. 1992).
In vivo reversibility of drug resistance by CsA has been reported in other, mostly non-solid tumour models. In ascites tumour models, Slater et al. (1986) found a correction of daunorubicin resistance by CsA on a daunorubicin-resistant subline of the Ehrlich ascites tumour in vivo, and they also described enhancement of the cytotoxicity of daunorubicin by CsA to the parental Ehrlich ascites and hepatoma 129 (Meador et al. 1987). Boesch et al. (1991a), however, did not find any effect of CsA on vincristine cytotoxicity to an MDR variant of the murine monocytic leukemia P388. Only Osieka et al. (1986) published a study about a solid tumour and showed enhancement of etoposide cytotoxicity by CsA to a human embryonal carcinoma in nude mice. We feel that our tumour model is, therefore, a valuable one, as it is both a syngeneic, and a solid, MDR-positive tumour.

Although our experiments suggest potential use for CsA in the clinical setting, results in the few trials reported so far have not yet substantiated its role, as they are not unequivocal. Sonneveld and Nooter (1990) showed the possibility of eliminating $m d r l$-positive acute myeloid leukemia cells by adding CsA to an ineffective treatment schedule. In a very recent report they described reversal of clinical drug resistance in patients with multiple myeloma after addition of CsA to the combination chemotherapy (Sonneveld et al. 1992). Response was correlated with Pgp and $m d r l$ expression. Steady-state plasma levels of CsA were about $1000 \mu \mathrm{g} / \mathrm{l}$. Verweij et al. (1991) tested CsA as a resistance-modifying agent in combination with epidoxorubicin in colorectal cancer. In four out of four tumour samples they showed the ability of CsA to enhance daunorubicin uptake by flow cytometry. Despite this observation, only 1 patient out of 24 had a partial response, while 2 of the patients who showed enhanced daunorubicin uptake in vitro had progressive disease. The CsA levels they reported seem quite high and adequate: peak levels of about $6000 \mathrm{ng} / \mathrm{ml}$ and levels around $1000 \mathrm{ng} / \mathrm{ml} 18 \mathrm{~h}$ later. Similar CsA levels were achieved in a clinical trial in renal cell cancer patients with the combination CsA plus vinblastine. No response was found in 15 patients (Rodenburg et al. 1991). Although $m d r$ levels or Pgp expression were not determined in these studies, it is likely that a substantial number of these 39 patients expressed Pgp in their tumours, as in other studies colon carcinoma as well as renal cell cancer was found to be $m d r$ - or Pgp-positive in the majority of the patients (Mizoguchi et al. 1990; Weinstein et al. 1991; Kanamaru et al. 1989; Mickisch et al. 1990; Van Kalken et al. 1991). Moreover, Kanamaru et al. (1989) and Mickisch et al. (1990) showed that Pgp expression in renal cell carcinomas correlated with resistance in primary cell cultures in vitro to doxorubicin and vinblastine, which could be reversed by chemosensitizers. The clinical trials by Rodenburg et al. (1991) and Verweij et al. (1991) are the only studies that dealt exclusively with tumours from organs that inherently have a high expression level of Pgp. Other studies were carried out in heavily pretreated patients or patients with advanced disease. In these studies, a clear response was found in a trial with patients with myeloma or lymphoma resistant to vincristine/doxorubicin/dexamethasone: 3 out of $8 \mathrm{pa}$ tients responded to the addition of verapamil to the drug regimen, while 6 of these 8 patients exhibited Pgp expression on their tumour cells (Dalton et al. 1989). So this last study and 
the study by Sonneveld et al. (1992) clearly suggest a benefical role of resistance-modifying agents.

So far only clinical trials with haematological disorders have been succesful in reversing MDR. In solid tumours no responses were found. We cannot compare our experimental data with clinical trials, but we show in our model the feasibility of reversing intrinsic MDR in a solid tumour in vivo. Adequate levels of the chemosensitizer CsA could be obtained at the tumour site by a vascular route, and this rendered a suboptimal dose of doxorubicin effective. Our results, obtained in a syngeneic, solid tumour model therefore suggest that there may still be a place for chemosensitizers in the chemotherapy of MDR solid tumours.

Acknowledgements. We would like to thank A. M. Bijma, H. J. Elst, and W. P. van Schalkwijk for their skilful technical assistance.

\section{References}

Boesch D, Gavériaux C, Jachez B, Pourtier-Manzanedo A, Bollinger P, Loor F (1991a) In vivo circumvention of P-glycoprotein-mediated multidrug resistance of tumor cells with SDZ PSC 833. Cancer Res 51:4226-4233

Boesch D, Muller K, Pourtier-Mabzanedo A, Loor F (1991b) Restoration of daunomycin retention in multidrug-resistant P388 cells by submicromolar concentrations of SDZ PSC 833, a nonimmunosuppressive cyclosporin derivative. Exp Cell Res 196:26-32

Carmichael J, DeGraff WG, Gazdar AF, Minna JD, Mitchell JB (1987) Evaluation of a tetrazolium-based semiautomated colorimetric assay: assessment of chemosensitivity testing. Cancer Res 47:936-942

Dalton WS, Grogan TM, Meltzer PS, Scheper RJ, Durie BGM, Taylor CW, Miller TP, Salmon SE (1989) Drug-resistance in multiple myeloma and non-Hodgkin's lymphoma: detection of P-glycoprotein and potential circumvention by addition of verapamil to chemotherapy. J Clin Oncol 7:415-424

Fojo AT, Ueda K, Slamon DJ, Poplack DG, Gottesman MM, Pastan I (1987) Expression of a multidrug-resistance gene in human tumors and tissues. Proc Natl Acad Sci USA 84:265-269

Ford JM, Hait WN (1990) Pharmacology of drugs that alter multidrug restistance in cancer. Pharmacol Rev 42:155-199

Gavériaux C, Boesch D, Boelsterli JJ, Bollinger P, Eberle MK, Hiestand P, Payne T, Traber R, Wenger R, Loor F (1989) Overcoming multidrug resistance in Chinese hamster ovary cells in vitro by cyclosporin $\mathrm{A}$ (Sandimmune) and non-immunosuppresive derivatives: $\mathrm{Br} \mathrm{J}$ Cancer 60:867-871

Gheuens EEO, Van Bockstaele DR, Van der Keur M, Tanke HJ, Van Oosterom AT, De Bruijn EA (1991) Flow cytometric double labeling technique for screening of multidrug resistance. Cytometry $12: 636-644$

Goldstein LJ, Galski H, Fojo A, Willingham M, Lai S-L, Gazdar A, Pirker R, Green A, Crist W, Brodeur GM, Lieber M, Cossman J, Gottesman MM, Pastan I (1989) Expression of a multidrug resistance gene in human cancers. JNCI 81:116-124

Kanamaru H, Kakehi Y, Yoshida O, Nakanishi S, Pastan I, Gottesman MM (1989) MDR1 RNA levels in human renal cell carcinomas: correlation with grade and prediction of reversal of doxorubicin resistance by quinidine in tumor explants. JNCI 81:844-849

Kartner N, Evernden-Porelle DE, Bradley G, Ling V (1985) Detection of P-glycoprotein in multidrug-resistant cell lines by monoclonal antibodies. Nature 316:820-823

Kaye SB (1990) Reversal of multidrug resistance. Cancer Treat Rev 17 [Suppl A]:37-43

Los G, Nagel JD, McVie JG (1990) Anti-tumor effect of cisplatin, carboplatin, mitoxantrone, and doxorubicin on peritoneal tumor growth after intraperitoneal and intravenous chemotherapy: a comparative study. Sel Cancer Ther 6:73-82
Marquet RL, Westbroek DL, Jeekel J (1984) Interferon treatment of a transplantable rat colon adenocarcinoma: importance of tumor site. Int J Cancer 33:689-692

Meador J, Sweet P, Stupecky M, Wetzel M, Murray S, Gupta S, Slater L (1987) Enhancement by cyclosporin A of daunorubicin efficacy in Ehrlich ascites carcinoma and murine hepatoma 129. Cancer Res 47:6216-6219

Mickisch GH, Roehrich K, Koessig J, Forster S, Tschada RK, Alken PM (1990) Mechanisms and modulation of multidrug resistance in primary human renal cell carcinoma. J Urol 144:755-759

Mizoguchi T, Yamada K, Furukawa T, Hidaka K, Hisatsugu T, Shimazu H, Tsuruo T, Sumizawa T, Akiyama S-i (1990) Expression of the MDR1 gene in human gastric and colorectal carcinomas. JNCI 82:1679-1683

Osieka R, Seeber S, Pannenbäcker R, Soll D, Glatte P, Schmidt CG (1986) Enhancement of etoposide-induced cy totoxicity by cyclosporin A. Cancer Chemother Pharmacol 18:198-202

Pennock GD, Dalton WS, Roeske WR, Appleton CP, Mosley K, Plezia P, Miller TM, Salmon SE (1991) Systemic toxic effects associated with high-dose verapamil infusion and chemotherapy administration. JNCI 83:105-110

Rodenburg CJ, Nooter K, Herweijer H, Seynaeve C, Oosterom R, Stoter G, Verweij J (1991) Phase II study of combining vinblastine and cyclosporin-A to circumvent multidrug resistance in renal cell cancer. Ann Oncol 2:305-306

Rogan AM, Hamilton TC, Young RC, Klecker RW, Ozols RF (1984) Reversal of Adriamycin resistance by verapamil in human ovarian cancer. Science 224:994-996

Sikic BL, Yahanda AM, Adler KM, Fisher B, Brophy NA, Halsey J, Gosland MP, Lum BL (1992) Use of cyclosporin to reverse drug resistance (abstract). Ann Oncol 3 [Suppl 1]:63

Silbermann MH, Boersma AWM, Janssen ALW, Scheper RJ, Herweijer H, Nooter K (1989) Effects of cyclosporin A and verapamil on the intracellular daunorubicin accumulation in Chinese hamster ovary cells with increasing levels of drug-resistance. Int $\mathrm{J}$ Cancer 44:722-726

Slater LM, Sweet P, Stupecky M, Wetzel MW, Gupta S (1986) Cyclosporin A corrects daunorubicin resistance in Ehrlich ascites carcinoma. Br J Cancer 54:235-238

Sonneveld P, Nooter K (1990) Reversal of drug-resistance by cyclosporin- $\mathrm{A}$ in a patient with acute myelocytic leukaemia. $\mathrm{Br} J$ Haematol 75:208-211

Sonneveld P, Durie BGM, Lokhorst HM, Marie JP, Solbu B, Suciu S, Zittoun R, Löwenberg B, Nooter K (1992) Modulation of multidrugresistant multiple myeloma by cyclosporin. Lancet 340:255-259

Thiebaut F, Tsuruo T, Hamada H, Gottesman MM, Pastan I, Willingham MC (1987) Cellular localization of the multidrug-resistance gene product P-glycoprotein in normal human tissues. Proc Natl Acad Sci USA 84:7735-7738

Twentyman PR, Reeve JG, Koch G, Wright KA (1990) Chemosensitisation by verapamil and cyclosporin $\mathrm{A}$ in mouse tumour cells expressing different levels of P-glycoprotein and CP22 (sorcin). Br J Cancer 62:89-95

Twentyman PR, Wright KA, Wallage HM (1992) Effects of cyclosporin $\mathrm{A}$ and a nonimmunosuppresive analogue $O$-acetyl cyclosporin A, upon growth of parent and multidrug resistant human lung cancer cells in vitro. Br J Cancer 65:335-340

Van Kalken CK, Van der Valk P, Hadisaputro MMN, Pieters R, Broxterman HJ, Kuiper CM, Scheffer GL, Veerman AJP, Meyer CJLM, Scheper RJ, Pinedo HM (1991) Differentiation dependent expression of $\mathrm{P}$-glycoprotein in the normal and neoplastic human kidney. Ann Oncol 2:55-62

Verweij J, Herweijer $\mathrm{H}$, Oosterom R, Van der Burg MEL, Planting ASTh, Seynaeve C, Stoter G, Nooter K (1991) A phase II study of epidoxorubicin in colorectal cancer and the use of cyclosporin- $\mathrm{A}$ in an attempt to reverse multidrug resistance. Br J Cancer 64:361-364

Weinstein RS, Jakate SM, Dominguez JM, Lebovitz MD, Koukoulis GK, Kuszak JR, Klusens LF, Grogan TM, Saclarides TJ, Roninson IB, Coon JS (1991) Relationship of the expression of the multidrug resistance gene product (P-glycoprotein) in human colon carcinoma to local tumor aggressiveness and lymph node metastasis. Cancer Res 51:2720-2726 